\title{
Perencanaan Program Interpretasi Untuk Mendukung Kegiatan Ekowisata Di Citamiang Bogor
}

\author{
Widya Weullas, Meizar Rusli, Devi Roza K. Kausar \\ meizar@univpancasila.ac.id \\ Program Studi Pariwisata, Fakultas Pariwisata, Universitas Pancasila
}

\begin{abstract}
Abstrak
Penelitian ini bertujuan mengukur tingkat kepentingan daya tarik ekowisata Citamiang, Jawa Barat, bagi wisatawan dan juga kepercayaan wisatawan terhadap daya tarik tersebut. Sesuai dari hasil analisis Fishbein bahwa atraksi yang sangat dipercaya sebagai daya tarik ekowisata adalah atraksi trek herbal yakni dengan skor 2.04. Trek herbal memiliki point edukasi yang penting untuk wisatawan yang berkunjung ke Citamiang. Sedangkan sikap konsumen terbesar ada di atribut Jalan, yakni sebesar 10,43. Infrastruktur yang ada di Citamiang memang sudah dianggap baik oleh wisatawan. Dari hasil tersebut, dqpat dibuat program interpretasi verbal dan non verbal yang sesuai untuk daya tarik ekowisata ini yaitu 'Meet The Herbs' sebagai program verbal dan 'Find More Indonesia' sebagai program non verbal. Sasarannya adala remaja-dewasa, karena karakteristik wisatawan yang datang ke Citamiang didominasi oleh remaja-dewasa. Program tersebut ditujukan agar wisatawan dapat menikmati dan sekaligus mendapatkan edukasi lingkungan.
\end{abstract}

Kata Kunci: program interpretasi, ekowisata, wisatawan.

\begin{abstract}
This research aims to measure tourists attitude toward the ecotourism attractions of Citamiang, West Java, and tourists' belief in the attraction using Fishbein model. The analysis shows that the herbal track is one attraction that the tourists belief most to be most attractive with the score of 2.04. The herbal track has an important educational point for tourist who visiting Citamiang. While Infrastructure is the attribute that tourists have most positive attitude with the score of 10.43. Infrastructure in Citamiang is already considered good by tourists. From this findings, two interpretation programs are made, one verbal and the other, non verbal. The verbal interpretation program is called 'Meet The Herbs' and the non verbal is 'Find More Indonesia'. The target market is youth to adults. The program is intended for tourists to enjoy and simultaneously experience environmental education.
\end{abstract}

Keywords: interpretation program, ecotourism, tourists. 


\section{Pendahuluan}

Citamiang, sebuah daya tarik ekowisata, terletak di Hutan Pangkuan Desa (HPD) Tugu Utara yang berada di Desa Tugu Utara, Kecamatan Cisarua, Kabupaten Bogor, Provinsi Jawa Barat. Citamiang memiliki luas wilayah 610,64 Ha dan dikelola oleh Lembaga Masyarakat Desa Hutan. Ekowisata merupakan kegiatan wisata yang memanfaatkan lingkungan alam dengan prinsip terdiri dari kegiatan yang berbasis alam, secara ekologis berkelanjutan, mengandung unsur pendidikan lingkungan, melibatkan masyarakat dan biasanya dikonsumsi oleh wisatawan minat khusus ekowisata (Avenzora, 2008). Prinsip ekowisata dan pariwisata berkelanjutan tentunya memiliki tujuan yang sama dimana agar semua sumberdaya yang ada di suatu kawasan terjaga keasliannya dan masyarakat ikut berperan aktif didalamnya. Ekowisata juga diartikan suatu konsep untuk menciptakan dan memuaskan suatu keinginan akan alam, tentang mengeksploitasi potensi wisata untuk konservasi dan pembangunan dan tentang mencegah dampak negatifnya terhadap ekologi, kebudayaan dan keindahan (Western 1995 dalam Avenzora 2008:14). Kegiatan ekowisata harus mempertimbangkan empat aspek penting yakni grup kecil dalam kegiatannya, nilai kealamiannya, pengawasan dari sisi keberlanjutannya dan standar edukasi yang harus diberikan kepada wisatawan (Lorant, 2014). Nai (2014) dalam Moscardo (2014) menjelaskan bahwa edukasi kawasan terdapat dalam interpretasi. Interpretasi diartikan suatu misi yang didasarkan pada proses komunikasi yang membentuk koneksi emosional dan intelektual diantara ketertarikan pendengar dan maksud yang melekat pada sumberdaya yang ada di kawasan.

Berwisata atau berekreasi menjadi suatu tren yang mana semua kalangan mencari kegiatan untuk menikmati waktu luangnya. Salah satu destinasi wisata yang belakangan ini mulai marak dan digemari banyak kalangan adalah wisata yang dikemas dengan unsur-unsur edukatif ini wisatawan diharapkan tidak hanya mendapatkan kesenangan saja, namun juga bisa mendapatkan inspirasi ataupun wawasan yang luas. Wisatawan yang datang ke Citamiang selain mendapat kembali kesegaran dari nuansa alamnya juga diharapkan dapat mengetahui dan mengenal apa saja yang terdapat di kawasan baik dari sisi lingkungan maupun tradisi masyarakat sekitar. Interpretasi lingkungan dapat dikatakan sebagai seni untuk menjelaskan keadaan lingkungan baik itu flora, fauna, gejala alam ataupun bentang alam yang ada di suatu kawasan kepada wisatawan.

Untuk memenuhi keinginan para calon wisatawan tersebut, sangat jelas diperlukan sesuatu yang menjembatani atau menghubungkan antara sumberdaya yang ada di Citamiang dengan wisatawan yang datang ke kawasan tersebut. Secara garis besar interpretasi menjadi salah satu cara untuk menyampaikan informasi yang ada di suatu kawasan secara benar kepada calon wisatawan. Interpretasi adalah tangan pertama untuk memberikan wisatawan sebuah pengalaman baru (Tilden, 1957 dalam Marson 2008).

Membuat suatu program interpretasi harus mempertimbangkan kualitas supply yang dirasakan oleh wisatawan yang sedang melakukan aktivitas. Interpretasi berkaitan erat dengan Supply yang ada di kawasan. Supply yang ada tentunya memiliki kualitas tersendiri bagi wisatawan yang datang. Interpretasi harus didukung dengan suatu program yang mumpuni, dan pengembangan kapasitas yang diperuntukkan untuk masyarakat lokal (Bowman, 2011). Di sisi lain, sebuah fenomena yang sedang terjadi di masyarakat dapat dijadikan sebagai bahan interpretasi, fenomena yang terjadi baik sosial budaya maupun alam dapat menjadi pengalaman baru bagi Wisatawan (O'Sullivan 2010). Interpretasi sangat dibutuhkan di Citamiang agar

Volume 7 No.1 Juni 2019, ISSN: 2339-1987 
wisatawan yang datang

setidaknya paham bahwa lingkungan sekitarnya harus terjaga keasliannya dan bonusnya adalah edukasi herbal yang bahkan dapat diceritakan kembali kepada rekannya.

\section{Tinjauan pustaka}

Ceballos-Lascurain (1999:12) menjelaskan bahwa daya tarik utama dari kawasaan-kawasan alami yang dijadikan sebuah destinasi adalah bentang alamnya, satwa liar dan flora, serta budaya yang ada di sekitar kawsan. Libosada (1998) dalam Alikodra (2012:332) menjelaskan bahwa dalam konteks pariwisata berkelanjutan yang diseusaikan dengan ciri dan kegiatannya maka pariwisata dapat dibedakan menjadi ekowisata dan wisata masal. Alikodra (2012:333) menjelaskan bahwa ekowisata bertumpu pada empat hal penting yang mana berhubungan langsung dengan pembangunan berkelanjutan yaitu:

1. Penyelamatan fungsi-fungsi ekosistem sehingga kehati dapat diselamatkan

2. Meningkatkan kondisi sosial ekonomi masyarakat

3. Melindungi dan melestarikan keanekaragaman budaya dan masyarakatnya dan

4. Meningkatkan sumber-sumber devisa negara

INDECON (1996) dalam Muntasib (2009:22) mendefinisikan ekowisata adalah penyelenggaraan kegiatan wisata yang bertanggung jawab di tempat-tempat alami dan daerah-daerah yang dibuat berdasarkan kaidah alam yang mendukung upaya-upaya pelestarian lingkungan (alam dan kebudayaan) dan meningkatkan kesejahteraan masyarakat sekitar. Ekowisata dalam Ceballos-Lascurain (1996:20) lebih mengacu kepada suatu perjalanan ke area yang tidak terganggu dan atau tidak terkontaminasi dengan maksud tujuan untuk studi dan menikmati keindahan alam serta satwa dan tumbuhan liar, sesuai dengan kondisi pada saat ditemukannya area tersebut.

Eplerwood dalam The Ecotourism Society (1999:67) memaparkan terdapat delapan prinsip ekowisata, yaitu:

a. Mencegah dan meminimalkan dampak dari kegiatan wisatawan terhadap alam dan budaya yang disesuaikan dengan sifat dan karakter alam dan budaya setempat.

b. Pendidikan konservasi lingkungan. Memberikan edukasi kepada wisatawan dan masyarakat setempat akan pentingnya arti konservasi yang dapat dilakukan secara langsung di alam.

c. Pendapatan langsung untuk kawasan. Mengatur agar kawasan yang digunakan untuk ekowisata dan manajemen pengelolaan kawasan pelestarian dapat menerima langsung penghasilan atau pendapatan. Retribusi dan conservation tax dapat digunakan secara langsung untuk membina, melestarikan dan meningkatkan kualitas kawasan pelestarian alam.

d. Keterlibatan masyarakat dalam perencanaan. Masyarakat diajak dalam merencanakan pengembangan ekowisata dan pengawasan peran masyarakat di harapkan ikut secara aktif.

e. Penghasilan masyarakat. Memberikan keuntungan secara nyata terhadap ekonomi masyarakat dari kegiatan ekowisata sehingga mendorong masyarakat dalam menjaga kelestarian kawasan.

f. Menjaga keharmonisan dengan alam. Semua upaya pengembangan 
termasuk pengembangan fasilitas harus tetap menjaga keharmonisan dengan alam.

g. Daya dukung lingkungan. Pada umumnya lingkungan alam mempunyai daya dukung yang lebih rendah dengan daya dukung kawasan buatan. Kegiatan wisata harus memperhatikan daya dukung lingkungan agar kelestarian kawasan tetap terjaga.

h. Peluang penghasilan pada porsi yang besar terhadap Negara. Apabila suatu kawasan pelestarian dikembangkan untuk ekowisata, maka devisa dan belanja wisatawan dapat dinikmati oleh Negara atau Negara bagian atau pemerintah setempat.

- Pariwisata

Dalam Alikodra (2013:328) menyebutkan bahwa pariwisata global tumbuh dengan pesat dan telah menjadi industri raksasa dunia, sejak tahun 1999 pendapatan nasional bruto dunia, perkembangannya telah mencapai $12 \%$ (US. Dept. Of Commerce, 1990). Terdapat tiga elemen dasar dalam pertumbuhan pariwisata dimana adanya kegiatan manusia yang melakukan perjalanan, adanya obyek yang menarik perhatian Wisatawan, dan adanya manajemen pariwisata yang memadai. Menurut Mason (2008:7) pariwisata dikatakan sebagai multi dimensi yang dapat dipisah-pisahkan menurut organisasi atau bidang tertentu, pernyataan tersebut didasari dari pernyataan Prosser (1998) yang mana menyebutkan terdapat dua variable utama dalam pariwisata yaitu hubungan daerah asal dan motivasi untuk melakukan suatu perjalanan. Sejalan dengan Cooper et al (1998:23) yang mana menuliskan bahwa pariwisata adalah multi dimensi yang meliputi berbagai kehidupan dan berbagai aktivitas yang ekonomi yang berbeda di dalamnya.
Hermantoro (2015:14) pariwisata didefinisikan hanya sebagai sebuah perjalanan untuk kepentingan rekreasi, liburan ataupun kunjungan keluarga dalam jangka waktu yang relatif pendek. Sedangkan menurut Spillane (1994: 63-72) suatu objek wisata atau destinasi, harus meliputi 5 (lima) unsur yang penting agar wisatawan dapat merasa puas dalam menikmati perjalanannya yakni Atraksi, Infrastruktur, fasilitas, transportasi dan hospitality.

\section{- Supply (Penawaran)}

Penawaran menurut Avenzora (2008) adalah segala sesuatu baik barang ataupun jasa yang ditawarkan kepada Wisatawan pada suatu kawasan wisata pada waktu, jumlah dan harga tertentu. Penawaran wisata akan berkaitan dengan apa dan berapa banyak yang ditawarkan, kepada siapa ditawarkan dan kapan waktu penawaran tersebut ditawarkan. Sejalan dengan pengertian tersebut Hermantoro (2015:170) menjelaskan bahwa faktor penawaran dapat berupa ruang geografis, karakteristik ekonomi dan sosial budaya destinasi pariwisata, namun bahasan disini adalah disudutkan pada sebuah ruang yang dapat dikomersialkan yang bertujuan sebagai destinasi pariwisata. Oka A. Yoeti (2008) menjelaskan bahwa penawaran (supply) dalam pariwisata meliputi semua macam produk dan pelayanan/jasa yang dihasilkan oleh kelompok perusahaan industri pariwisata sebagai pemasok, yang ditawarkan baik kepada wisatawan yang datang secara langsung atau yang membeli melalui Agen Perjalanan (AP) atau Biro Perjalanan Wisata (BPW) sebagai perantara.

- Interpretasi

- Interpretasi adalah pelayanan untuk Wisatawan yang berkunjung ke taman, hutan, dan area semacamnya, dengan demikian Wisatawan yang datang dapat berelaksasi dan mendapat inspirasi (Sharpe 1982:4). Sedangkan Tilden

Volume 7 No.1 Juni 2019, ISSN: 2339-1987 
(1957:11) mengemukakan bahwa program interpretasi adalah alat untuk menghubungkan antara apa yang seharusnya didapatkan oleh Wisatawan pada suatu lingkungan alam dengan apa yang seharusnya ditampilkan. Interpretasi tidak tiba-tiba menceritakan apa yang dipajang atau menjelaskan sesuatu dari kepribadian atau pengalaman Wisatawan menjadi tidak sempurna. Walin (dalam Sharpe 1982) sebagai Kepala Taman Metropolitan Cleveland mengatakan bahwa Interpretasi adalah salah satu cara pelayanan untuk membantu Wisatawan supaya tergugah rasa sensitifnya dalam merasakan keindahan alam, kekomplekannya, hubungan lingkungan, dan rasa kagum dan mempunyai keingintahuan.

- Definisi penafsiran Tilden (1957:4) interpretasi selalu mengacu pada kegiatan pendidikan. Namun, mendidik hanya untuk meningkatkan kepuasan yang didapat dari pengalaman rekreasi. Sejalan dengan penafsiran tersebut Cameron-Smith (1977) dalam Wearing (2009:107) seharusnya badan pengelola menyadari bahwa tidak cukup hanya untuk menafsirkan suatu kawasan yang diakui sebagai sumber untuk perubahan lingkungan maka dari itulah media interpretasi dapat dijadikan sebuah media untuk mendidik.

Veverka (1994:23-25) menjelaskan bahwa penyampaian program interpretasi terdapat dua macam teknik komunikasi yaitu verbal dan nonverbal:

a. Komunikasi verbal

Kunci utama yang dipertimbangkan adalah pemilihan kata yang digunakan dalam penyampaian interpretasi sehingga dapat menyampaikan banyak pesan yang tersembunyi. Pesan verbal mencakup musik latar, tipe suara menurut jenis kelamin seperti laki-laki atau perempuan, muda atau tua, danjenis obyek yang merupakan bagian dari penciptaan gambaran yang diinginkan oleh pendengar. Pesan ini juga merupakan komponen penghubung antara pendengar dengan pesan-pesan yang ingin disampaikan.

b. Komunkasi non-verbal

Komunikasi ini memanfaatkan alat indera. Penyampaian interpretasi dapat dilakukan dengan menggunakan berbagai alat atau media interpretasi yang merupakan salah satu cara, metode, perekam suara atau peralatan yang bisa menyampaikan pesan interpretasi kepada publik. Komponen non-verbal diantaranya suara, aroma, rasa, tekstur, warna, symbol, penggunaan ruang, bahasa tubuh dan waktu.

Menurut Tilden (1957:9) prinsip interpretasi harus sangat diperhatikan agar informasi yang disampaikan sempurna dan tidak ada yang dirahasiakan yang mana terdapat 6 prinsip interpretasi yaitu:

a. Suatu interpretasi yang tidak ada kaitannya antara apa yang diperagakan atau diuraikan dengan apa yang dialami atau kepribadian personalitas para Wisatawan akan merupakan hal yang siasia

b. Informasi, penerangan atau materi yang sejenis dengan itu saja bukanlah interpretasi. Interpretasi adalah ungkapan rahasia yang didasarkan atas informasiinformasi, namun interpretasi berbeda dan lebih luas daripada informasi. Kedalam interpretasi diharuskan memasukan unsur-unsur informasi. 
c. Interpretasi adalah suatu seni yang menggabungkan bermacam-macam seni baik bersifat ilmiah, sejarah atau arsitektur atau sesuatu seni yang pada suatu tingkatan dapat diajarkan kepada orang lain

d. Cara mengutarakan interpretasi bukanlah dengan suatu perintah melainkan dengan pancingan atau persuasif

e. Interpretasi bermaksud mempertunjukkan secara jelas danbukan sebagian-sebagian. Interpretasi sebaiknya tidak boleh dirahasiakan atau hanya boleh digunakan oleh golongan tertentu saja.

f. Interpretasi yang ditujukan pada anakanak tidak dapat dipakai untuk orang dewasa karena masing-masing mempunyai pendekatan yang berbeda.

Pada dasarnya Interpretasi adalah untuk memberikan semua informasi terkait kawasan, menurut Muntasib (2003:23) jalur interpretasi adalah yang digunakan oleh orang-orang yang memasuki kawasan dengan lingkungan yang sangat menarik untuk tujuan menghargai nilainilai kawasan yang dipandu oleh petugas kawasan tersebut. Moscardo (2014:472) menafsirkan bahwa menginterpretasikan warisan dapat dan memberikan dimensi penting pada pengalaman beberapa Wisatawan dalam kondisi yang tepat, ini juga dapat mendukung strategi pengelolaan Wisatawan di tempat.

- Ekowisata dan Interpretasi

Avenzora (2008:18) menyatakan bahwa ekowisata adalah ruh dan jiwa dari pariwisata. Ekowisata tidak dapat dipisahkan dari sisi edukasi yang ada disuatu kawasan karena sejalan dengan prinsip ekowisata dalam Muntasib (2009:19) yakni Nature Based dimana produk dan pasar berdasarkan pada alam. Ecological Sustainable dimana pelaksanaan dan manajemennya harus pberkelanjutan,
Enviromental Educative pendidikan bagi pengelola dan Wisatawana, Local Community dimana masyarakat harus ikut berperan aktif terhadap perkembangannya, dan memberikan kepuasan terhadap wisatawan.

Dari prinsip tersebut ekowisata tidak dapat dilepaskan dari Interpretasi Lingkungan dimana menurut Zalatan (1996:4) dalam penelitiannya mengenai Ekowisata di Kepulauan Virgin yakni ekowisata masih terkait secara positif dengan pendidikan, pendapatan dan usia. Hubungan dengan usia mungkin disebabkan oleh tingginya biaya ekowisata. Data yang tersedia menyarankan biaya \$200/hari. Ini jelas di atas kemampuan finansial para pemuda pelancong di Amerika.

\section{Metode Penelitian}

Penelitian ini menggunakan Mix Method atau campuran, dimana penelitian ini menggunakan pendekatan metode kualitatif dan kuantitatif (Creswell, 2010). Dilaksanakan pada bulan Oktober sampai Desember 2017, tahapan pertama pada penelitian ini adalah pengumpulan data kualitatif dimana potensi yang ada di Citamiang yang sudah diinventarisasi akan dideskripsikan terlebih dahulu. Potensi yang akan dideskripsikan adalah Ekologi (Flora, Fauna) dan keindahan alam (Bentang Alam), variabel tersebut diambil dari teori Ceballos- Lascurain (1995) sebagai daya tarik ekowisata. Selanjutnya, setelah atrakasi ekowisata yang ada di Citamiang wisata teridentifikasi, maka variabel tersebut dijadikan sebagai kata kunci untuk indikator dalam kuisioner untuk wisatawan. Indikator tersebut akan dianalisis dengan metode Fishbein untuk mengetahui tingkat kepercayaan dan kepentingan atraksi dari wisatawan.

Model Sikap Fishbein pada prinsipnya akan menghitung $\mathrm{A}_{\mathrm{o}}$ (Attitude toward the object), yaitu sikap seseorang terhadap sebuah objek, yang dikenali lewat atribut-atribut yang melekat pada objek tersebut (Ajzen, 1965).

Volume 7 No.1 Juni 2019, ISSN: 2339-1987 
Metode ini digunakan untuk mengukur tingkat kepentingan suatu daya tarik terhadap Wisatawan dan juga kepercayaan Wisatawan terhadap daya tarik tersebut. Atribut diambil tiga dari lima syarat daya tarik wisata menurut Spillane (1994) yakni Atraksi, Fasilitas, Infrastruktur.

4. Analisis

\section{Atraksi Ekowisata}

\section{- Nursery Herbal}

Nursery Herbal atau Persemaian Herbal adalah tempat atau areal untuk kegiatan memproses benih menjadi bibit herbal yang siap ditanam di media tanah langsung. Benih yang ada di Nursery ini difokuskan pada tanaman herbal yang mana bibit yang ada di area nursery diambil dari kawasan hutan Citamiang. Nursery ini dibuat dengan desain yang unik dan juga memakai material botol minuman yang sudah tidak terpakai dengan ukuran $2 \times 3 \mathrm{~m}$.

\section{- Camping Ground}

Camping Ground atau area perkemahan yang biasanya untuk beristirahat dari ramainya perkotaan, atau dari keramaian secara umum, untuk menikmati keindahan alam. Camping Ground dengan luas \pm 2 ha ini menjadi salah satu Atraksi bagi kawasan Citamiang. Camping Ground ini memiliki permukaan tanah yang landai yang dijadikan sebagai sarana untuk berkemah atau hanya berpiknik saja. Camping Ground ini dapat digunakan oleh kegiatan besar seperti Jambore atau kegiatan gathering lainnya.

\section{- Track Herbal}

Trek Herbal ini berada diluas area \pm 5 ha, panjang trek ini adalah $832 \mathrm{~m}$. Topografi yang berbukit dimana tidak terlalu menanjak dan banyak area landai menjadikan trek herbal ini memiliki keunggulan tersendiri bagi wisatawan. Trek herbal ini didesain untuk wisata edukasi yang menawarkan pengalaman berbeda. Desain trek herbal ditujukan agar wisatawan dapat mengeksplorasi tanaman herbal di sepanjang trek tersebut. Label tanaman diletakan pada tiap tanaman sesuai habitat aslinya pada saat ditemukan. Label tanaman akan ditemukan pada tiap tanaman herbal, label tanaman herbal tersebut telah dilengkapi sistem barcode dimana sistem barcode ini ditujukan untuk mendeteksi manfaat dan nama ilmiah tanaman, wisatawan dapat memakainya jika sudah menginstal aplikasi untuk membaca barcode. Ini menjadi sebuah media interpretasi modern yang telah diaplikasikan pada jalur trek herbal ini. Waktu tempuh dalam menyusuri trek herbal ini \pm 2 jam 15 menit dengan ritme jalan yang cukup santai.

\section{- Rumah Pemanen Hujan}

Rumah pemanen hujan (RPH) ditujukan untuk edukasi pengelolaan air hujan. Rumah pemanenhujan memiliki Konsep rumah ini adalah untuk memanfaatkan air hujan secara maksimal. Sebagian di alirkan ke tanah yang berkaitan dengan siklus hidrologi, kesuburan tanah dan air tanah. Sebagian ditampung untuk dimanfaatkan kebutuhan MCK di sekitar kawasan. Air tersebut tidak dapat dikonsumsi secara langsung karena belum ada pengujian lab, penggunaan air yang telah disaring dalam satelit pemanen hujan baru hanya sebatas dapat difungsikan untuk luar badan saja.

\section{- Café 1911}

Café 1911 adalah Atraksi yang letaknya sangat strategis dimana café tersebut berada sejajaran denga pintu masuk Citamiang. Nama café 1911 di ambil dari sejarah kawasan tersebut. Dimana pada masa 1911 kawasan ini dikuasai oleh kolonial belanda, dan penduduk lokal disini 
tidak bisa menikmati kawasan tersebut dan hanya jadi budak di tanahnya sendiri. Pada zaman dahulu kawasan ini difungsikan untuk pembangkit listrik untuk kawasan sekitar oleh Van Der Hough.

\section{- Selfie Point Capung}

Selfie Point menjadi penting untuk wisatawa merekoleksi perjalannya dimana dalam setiap perjalanan pasti mengabadikan sebuah moment lewat kamera. Selfie poit yang berbentuk sayap capung ini memang memiliki keunikan tersendiri yakni sayap capung diletakan diketinggian dengan memiliki latar belakang hutan pinus dan damar sehingga terlihat seperti sedang terbang. Aksesibilitas menuju area selfie Capung dapat ditempuh hanya dengan berjalan kaki. Letaknya 321 m dari Titik Nol Ciliwung. Lebar pejalan kaki hanya bisa dilalui 1 orang yakni $\pm 1 \mathrm{~m}-1,25$ $\mathrm{m}$. Wisatawan bisa menikmati dengan tidak harus menguras banyak energy ataupun materi karena sudah termasuk dengan harga tiket masuk.

\section{Analisis Fishbein}

\section{Tingkat Kepercayaan}

- Atraksi

\begin{tabular}{|l|r|r|r|r|r|r|r|}
\hline \multirow{2}{*}{ Atribut } & \multicolumn{9}{|c|}{ Believe } \\
\cline { 2 - 8 } & & & & & \multicolumn{2}{c|}{$\begin{array}{c}\text { Skor } \\
\text { Keperca } \\
\text { yaan }\end{array}$} \\
\hline $\begin{array}{l}\text { Atraksi } \\
\text { Nursery }\end{array}$ & 0 & 0 & 25 & 25 & 0 & 25 & 0,5 \\
\hline $\begin{array}{l}\text { Atraksi } \\
\text { Camping } \\
\text { Ground }\end{array}$ & 0 & 0 & 0 & 40 & 10 & 60 & 1,2 \\
\hline $\begin{array}{l}\text { Atraksi } \\
\text { Track }\end{array}$ & & & & & & & 1,4 \\
Herbal & 0 & 0 & 0 & 27 & 23 & 73 & 6 \\
\hline $\begin{array}{l}\text { Atraksi } \\
\text { Selfie Point } \\
\text { Capung }\end{array}$ & 0 & 0 & 25 & 25 & 0 & 25 & 0,5 \\
\hline $\begin{array}{l}\text { Atraksi } \\
\text { Rumah } \\
\text { Pemanen } \\
\text { Hujan }\end{array}$ & & & & & & & \\
\hline
\end{tabular}

\begin{tabular}{|l|r|r|r|r|r|r|r|}
\hline Atraksi & & & & & & & 1,1 \\
Café 1911 & 0 & 0 & 0 & 44 & 6 & 56 & 2 \\
\hline
\end{tabular}

- Infrastruktur

\begin{tabular}{|c|c|c|c|c|c|c|c|}
\hline \multirow{3}{*}{$\begin{array}{l}\text { Atribut } \\
\text { Jalan } \\
\text { Nursery }\end{array}$} & \multicolumn{7}{|c|}{ Believe } \\
\hline & \multirow{2}{*}{$\frac{-2}{0}$} & \multirow{2}{*}{$\frac{-1}{0}$} & \multirow{2}{*}{$\begin{array}{l}\mathbf{0} \\
0\end{array}$} & \multirow{2}{*}{$\frac{1}{10}$} & \multirow{2}{*}{$\begin{array}{r}2 \\
40\end{array}$} & \multicolumn{2}{|c|}{$\begin{array}{c}\text { Skor } \\
\text { Kepercayaan }\end{array}$} \\
\hline & & & & & & 90 & 1,80 \\
\hline $\begin{array}{l}\text { Jalan } \\
\text { Camping } \\
\text { Ground }\end{array}$ & 0 & 0 & 0 & 0 & 50 & 50 & 1 \\
\hline $\begin{array}{l}\text { Jalan } \\
\text { Track } \\
\text { Herbal }\end{array}$ & 0 & 0 & 0 & 34 & 16 & 52 & 1,04 \\
\hline $\begin{array}{l}\text { Jalan } \\
\text { Selfie } \\
\text { Point } \\
\text { Capung }\end{array}$ & 0 & 0 & 26 & 24 & 0 & 24 & 0,48 \\
\hline $\begin{array}{l}\text { Jalan } \\
\text { Rumah } \\
\text { Pemanen } \\
\text { Hujan }\end{array}$ & 0 & 0 & 0 & 12 & 38 & 88 & 1,76 \\
\hline $\begin{array}{l}\text { Jalan } \\
\text { Café } \\
1911\end{array}$ & 0 & 0 & 0 & 34 & 16 & 66 & 1,32 \\
\hline
\end{tabular}

- Fasilitas

\begin{tabular}{|l|r|r|r|r|r|r|r|}
\hline \multirow{2}{*}{ Atribut } & \multicolumn{7}{|c|}{ Believe } \\
\cline { 2 - 8 } & $\mathbf{- 2}$ & $\mathbf{- 1}$ & $\mathbf{0}$ & $\mathbf{1}$ & $\mathbf{2}$ & \multicolumn{2}{|c|}{ Skor Kepercayaan } \\
\hline $\begin{array}{l}\text { Fasilitas } \\
\text { Nursery }\end{array}$ & 0 & 0 & 0 & 10 & 40 & 90 & 1,8 \\
\hline $\begin{array}{l}\text { Fasilitas } \\
\text { Camping } \\
\text { Ground }\end{array}$ & & & & & & & \\
\hline $\begin{array}{l}\text { Fasilitas } \\
\text { Track }\end{array}$ & & & & & & & \\
Herbal & 0 & 0 & 0 & 0 & 50 & 100 & 1,48 \\
\hline $\begin{array}{l}\text { Fasilitas } \\
\text { Selfie }\end{array}$ & & & & & & & \\
$\begin{array}{l}\text { Point } \\
\text { Capung }\end{array}$ & 0 & 0 & 0 & 24 & 26 & 76 & 1,52 \\
\hline $\begin{array}{l}\text { Fasilitas } \\
\text { Rumah }\end{array}$ & & & & & & & \\
Pemanen & & & & & & & \\
Hujan & 0 & 0 & 0 & 10 & 40 & 90 & 1,8 \\
\hline $\begin{array}{l}\text { Fasilitas } \\
\text { Café } \\
1911\end{array}$ & & & & & & & \\
\hline
\end{tabular}




\section{Tingkat Kepentingan}

\section{- Atraksi}

\begin{tabular}{|l|r|r|r|r|r|r|r|}
\hline \multirow{2}{*}{ Atribut } & \multicolumn{7}{|c|}{ Evaluasi } \\
\cline { 2 - 8 } & $\mathbf{- 2}$ & $\mathbf{- 1}$ & $\mathbf{0}$ & $\mathbf{1}$ & $\mathbf{2}$ & \multicolumn{2}{|c|}{ Skor Evaluasi } \\
\hline $\begin{array}{l}\text { Atraksi } \\
\text { Nursery }\end{array}$ & 0 & 0 & 0 & 50 & 0 & 50 & 1 \\
\hline $\begin{array}{l}\text { Atraksi } \\
\text { Camping } \\
\text { Ground }\end{array}$ & 0 & & & & & & \\
\hline $\begin{array}{l}\text { Atraksi } \\
\text { Track }\end{array}$ & & & & & & & \\
Herbal & 0 & 0 & 0 & 30 & 20 & 70 & 1,40 \\
\hline $\begin{array}{l}\text { Atraksi } \\
\text { Selfie Point } \\
\text { Capung }\end{array}$ & 0 & 0 & 0 & 25 & 25 & 25 & 0,5 \\
\hline $\begin{array}{l}\text { Atraksi } \\
\text { Rumah } \\
\text { Pemanen } \\
\text { Hujan }\end{array}$ & & & & & & & \\
\hline $\begin{array}{l}\text { Atraksi Café } \\
\text { 1911 }\end{array}$ & 0 & 0 & 0 & 33 & 17 & 67 & 1,34 \\
\hline
\end{tabular}

\section{- Infrastruktur}

\begin{tabular}{|c|c|c|c|c|c|c|c|}
\hline \multirow{3}{*}{$\begin{array}{l}\text { Atribut } \\
\text { Jalan } \\
\text { Nursery }\end{array}$} & \multicolumn{7}{|c|}{ Evaluasi } \\
\hline & \multirow{2}{*}{$\begin{array}{r}-2 \\
0\end{array}$} & \multirow{2}{*}{$\begin{array}{r}-1 \\
0\end{array}$} & \multirow{2}{*}{$\begin{array}{l}\mathbf{0} \\
0\end{array}$} & \multirow{2}{*}{$\begin{array}{l}1 \\
0\end{array}$} & \multirow{2}{*}{$\begin{array}{r}2 \\
50\end{array}$} & \multicolumn{2}{|c|}{ Skor Evaluasi } \\
\hline & & & & & & 100 & 2 \\
\hline $\begin{array}{l}\text { Jalan } \\
\text { Camping } \\
\text { Ground }\end{array}$ & 0 & 0 & 0 & 13 & 37 & 87 & 1,74 \\
\hline $\begin{array}{l}\text { Jalan } \\
\text { Track } \\
\text { Herbal }\end{array}$ & 0 & 0 & 0 & 11 & 39 & 52 & 1,04 \\
\hline $\begin{array}{l}\text { Jalan } \\
\text { Selfie } \\
\text { Point } \\
\text { Capung }\end{array}$ & 0 & 0 & 0 & 24 & 26 & 24 & 0,48 \\
\hline $\begin{array}{l}\text { Jalan } \\
\text { Rumah } \\
\text { Pemanen } \\
\text { Hujan }\end{array}$ & 0 & 0 & 0 & 34 & 16 & 66 & 1,32 \\
\hline $\begin{array}{l}\text { Jalan } \\
\text { Café } \\
1911\end{array}$ & 0 & 0 & 0 & 45 & 5 & 55 & 1,1 \\
\hline
\end{tabular}

- Fasilitas

\begin{tabular}{|c|c|c|c|c|c|c|c|}
\hline \multirow{3}{*}{$\begin{array}{l}\text { Atribut } \\
\text { Fasilitas } \\
\text { Nursery }\end{array}$} & \multicolumn{7}{|c|}{ Evaluasi } \\
\hline & -2 & -1 & $\mathbf{0}$ & 1 & 2 & Skor & Iasi \\
\hline & 0 & 0 & 0 & 40 & 10 & 60 & 1,2 \\
\hline $\begin{array}{l}\text { Fasilitas } \\
\text { Camping } \\
\text { Ground }\end{array}$ & 0 & 0 & 0 & 22 & 28 & 78 & 1,56 \\
\hline $\begin{array}{l}\text { Fasilitas } \\
\text { Track } \\
\text { Herbal } \\
\end{array}$ & 0 & 0 & 0 & 29 & 21 & 71 & 1,42 \\
\hline $\begin{array}{l}\text { Fasilitas } \\
\text { Selfie } \\
\text { Point } \\
\text { Capung }\end{array}$ & 0 & 0 & 45 & 5 & 0 & 5 & 0,1 \\
\hline $\begin{array}{l}\text { Fasilitas } \\
\text { Rumah } \\
\text { Pemanen } \\
\text { Hujan }\end{array}$ & 0 & 0 & 38 & 12 & 0 & 12 & 0,24 \\
\hline $\begin{array}{l}\text { Fasilitas } \\
\text { Café } \\
1911\end{array}$ & 0 & 0 & 28 & 22 & 0 & 22 & 0,44 \\
\hline
\end{tabular}

\section{Analisis Sikap}

Kategori sikap dapat diketahui dengan menentukan skala interval terlebih dahulu. Perhitungan skala interval dilakukan dengan menentukan skor maksimun dan minimum sikap yang telah ditentukan. Skor maksimum ditentukan dengan mengalikan nilai evaluasi kepentingan dan kepercayaan dengan jumlah atribut yang digunakan. Skor maksimum adalah 24 yang mana di dapat dari $(2 \times 2 \times 6)$ dan skor minimumnya adalah -24 yang mana didapat dari $(-2 \times 2 \times 6)$ dan hitungan skala intervalnya yakni $(24-(-24)) / 5=$ 14,4. Jadi skala Interval untuk menentukan kategori adalah 14,4. Maka dari itu kategori sikap konsumen terbagi dalam 5 kelas, yaitu:

\begin{tabular}{|l|l|}
\hline \multicolumn{1}{|c|}{ Skala Penilaian } & Kategori \\
\hline$-24 \geq$ Nilai sikap $\leq-14,4$ & Sangat Tidak Baik \\
\hline$-14,4>$ Nilai sikap $\leq-4,8$ & Tidak baik \\
\hline$-4,8>$ Nilai sikap $\leq 4,8$ & Cukup baik \\
\hline $4,8>$ Nilai sikap $\leq 14,4$ & Baik \\
\hline $14,4>$ Nilai sikap $\leq 24$ & Sangat baik \\
\hline
\end{tabular}


- Siap Terhadap Atraksi

\begin{tabular}{|l|r|r|r|}
\hline \multicolumn{1}{|c|}{ Atribut } & \multicolumn{1}{|c|}{$\begin{array}{c}\text { Skor } \\
\text { Kepercayaan }\end{array}$} & $\begin{array}{c}\text { Skor } \\
\text { Evaluasi }\end{array}$ & \multicolumn{2}{c|}{$\begin{array}{c}\text { Sikap } \\
\text { Konsumen } \\
\text { Ao=ei.bi }\end{array}$} \\
\hline $\begin{array}{l}\text { Atraksi } \\
\text { Nursery }\end{array}$ & 0,5 & 1 & 0,50 \\
\hline $\begin{array}{l}\text { Atraksi } \\
\text { Camping } \\
\text { Ground }\end{array}$ & 1,2 & 1,3 & 1,56 \\
\hline $\begin{array}{l}\text { Atraksi } \\
\text { Track }\end{array}$ & & & \\
Herbal & 1,46 & 1,4 & \\
\hline $\begin{array}{l}\text { Atraksi } \\
\text { Selfie }\end{array}$ & & & \\
$\begin{array}{l}\text { Point } \\
\text { Capung }\end{array}$ & 0,5 & 0,5 & 0,25 \\
\hline $\begin{array}{l}\text { Atraksi } \\
\text { Rumah } \\
\text { Pemanen }\end{array}$ & & & \\
Hujan & & & 1,63 \\
\hline $\begin{array}{l}\text { Atraksi } \\
\text { Café }\end{array}$ & 1,22 & 1,34 & \\
1911 & & & \\
\hline Jumlah & 1,12 & 1,08 & \\
\hline
\end{tabular}

- Sikap Terhadap Infrastruktur

\begin{tabular}{|l|r|r|r|}
\hline \multicolumn{1}{|c|}{ Atribut } & \multicolumn{1}{|c|}{$\begin{array}{c}\text { Skor } \\
\text { Kepercayaan }\end{array}$} & \multicolumn{1}{c|}{$\begin{array}{c}\text { Skor } \\
\text { Evaluasi }\end{array}$} & $\begin{array}{c}\text { Sikap } \\
\text { Konsumen } \\
\text { Ao=ei.bi }\end{array}$ \\
\hline Jalan & 1,8 & 2 & 3,60 \\
Nursery & 1 & 1,74 & 1,74 \\
\hline $\begin{array}{l}\text { Jalan } \\
\text { Camping } \\
\text { Ground }\end{array}$ & & & \\
\hline Jalan & & 1,04 & \\
$\begin{array}{l}\text { Track } \\
\text { Herbal }\end{array}$ & 1,04 & & 1,08 \\
\hline $\begin{array}{l}\text { Jalan } \\
\text { Selfie }\end{array}$ & & & \\
$\begin{array}{l}\text { Point } \\
\text { Capung }\end{array}$ & 0,48 & 0,48 & \\
\hline $\begin{array}{l}\text { Jalan } \\
\text { Rumah } \\
\text { Pemanen }\end{array}$ & & & \\
Hujan & & & \\
\hline $\begin{array}{l}\text { Jalan Café } \\
\text { 1911 }\end{array}$ & 1,76 & 1,32 & \\
\hline Jumlah & 1,32 & 1,1 & 1,45 \\
\hline
\end{tabular}

- Sikap Terhadap Fasilitas

\begin{tabular}{|l|c|c|c|}
\hline \multicolumn{1}{|c|}{ Atribut } & $\begin{array}{c}\text { Skor } \\
\text { Kepercayaan }\end{array}$ & $\begin{array}{c}\text { Skor } \\
\text { Evaluasi }\end{array}$ & $\begin{array}{c}\text { Sikap } \\
\text { Konsumen } \\
\text { Ao=ei.bi }\end{array}$ \\
\hline $\begin{array}{l}\text { Fasilitas } \\
\text { Nursery }\end{array}$ & 1,8 & 1,2 & 2,16 \\
\hline $\begin{array}{l}\text { Fasilitas } \\
\text { Camping } \\
\text { Ground }\end{array}$ & 1,48 & 1,56 & 2,31 \\
\hline $\begin{array}{l}\text { Fasilitas } \\
\text { Track } \\
\text { Herbal }\end{array}$ & 2 & 1,42 & 2,84 \\
\hline $\begin{array}{l}\text { Fasilitas } \\
\text { Selfie } \\
\text { Point } \\
\text { Capung }\end{array}$ & 1,52 & 0,1 & 0,36 \\
\hline $\begin{array}{l}\text { Fasilitas } \\
\text { Rumah } \\
\text { Pemanen } \\
\text { Hujan }\end{array}$ & 1,8 & 0,24 & 0,18 \\
\hline $\begin{array}{l}\text { Fasilitas } \\
\text { Café 1911 }\end{array}$ & 1,54 & 0,44 & 0,68 \\
\hline Jumlah & & & 8,53 \\
\hline
\end{tabular}

Sikap konsumen memiliki penialaian yang berbeda terhadap atributnya. Sikap konsumen terhadap atribut atraksi yang ada di Citamiang menunjukan ada di kategori 'baik' yang memiliki jumlah skor sebesar 7.20 dimana ada di interval $4,8>$ Nilai sikap $\leq 14,4$. Kategori baik mengartikan bahwa atraksi yang ada dapat diterima dengan baik dan disukai oleh wisatawan dengan atraksi yang unggul terletak pada Track Herbal dengan Nilai Sikap Konsumen sebesar 2,04. Sikap konsumen tersebut menjadikanTrack Herbal memiliki respon positif dari wisatawan. Skor terendah dimiliki oleh Selfie Point Capung yang memiliki jumlah skor 0,25. Sikap konsumen terhadap selfie capung tidak terlalu baik dan kurang diminati oleh wisatawan.

Sikap konsumen terhadap atribut Jalan atau infrastruktur yang ada di Citamiang menunjukan ada di kategori 'baik' yang memiliki jumlah skor sebesar 10.43 dimana ada di interval 4,8 > Nilai sikap $\leq 14,4$. Kategori baik mengartikan bahwa infrastruktur yang sudah tersedia dapat diterima dengan baik dan disukai oleh wisatawan dengan 
Jalan yang unggul terletak pada Jalan menuju Nursery dengan Nilai Sikap Konsumen sebesar 3,04. Sikap konsumen tersebut menjadikan Jalan menuju Nursery memiliki respon positif dari wisatawan karena sudah sangat nyaman dailalui, medan dan serta jaraknya mudah dilalui. Skor terendah dimiliki oleh Selfie Point Capung yang memiliki jumlah skor 0,23. Sikap konsumen terhadap selfie capung tidak terlalu baik dan kurang diminati oleh wisatawan

Sikap konsumen terhadap atribut Fasilitas yang ada di Citamiang menunjukan ada di kategori 'baik' yang memiliki jumlah skor sebesar 8.53 dimana ada di interval 4,8 $>$ Nilai sikap $\leq 14,4$. Kategori baik mengartikan bahwa fasilitas yang telah tersedia dapat diterima dengan baik dan disukai oleh wisatawan dengan Jalan yang unggul terletak pada Jalan menuju Track Herbal dengan nilai sikap 2,84. Sikap konsumen tersebut menjadikan fasilitas yang ada di Track Herbal memiliki respon positif dari wisatawan karena fasilitas yang tersedia sudah dianggap 'baik' dan sikap wisatawan masih bisa menerima fasilitas yang sekarang sudah tersedia. Skor terendah dimiliki oleh Selfie Point Capung yang memiliki jumlah skor 0,23. Sikap konsumen terhadap selfie capung tidak terlalu baik dan kurang diminati oleh wisatawan.

- Rekomendasi Program Interpretasi

Sesuai dari hasil analisis Fishbein bahwa atraksi yang sangat dipercaya sebagai daya tarik ekowisata adalah traksi track herbal. Track herbal memiliki point edukasi yang sangat penting untuk wisatawan yang berkunjung ke Citamiang. Atraksi ini memiliki banyak sekali keunggulan didalamnya, diantaranya menanamkan system teknologi untuk mengakses pegetahuan mengenai herbal, selanjutnya tanaman herbal masih diletakan di habitat aslinya dan menjadikan pengetahuan baru bagi wisatawan mengenai habitat asli tanaman herbal yang ada di Citamiang. Tingkat kepentingan Track herbalpun sangat penting untuk ada dalam program wisata, dari hasil analisis bahwa track herbal menjadi yang utama untuk ada di dalam program interpretasi. Sikap wisatawan terhadap atraksi yang ada di Citamiang pada umumnya baik dan infrastruktur serta fasilitas yang ada sudah dapat memenuhi kebutuhan wisatawan saat ini.

Wisatawan yang datang pada umumnya hanya untuk berekreasi saja namun edukasi yang ada di lingkungan tidak sampai pada wisatawan yang datang, umumnya wisatwan yang datang adalah dewasa yang ingin menghabiskan waktu luangnya. Namun, seiring peningkatan angka kunjungan wisatwan yang datang ke Citamaing mulai terasa adanya perubahan kualitas lingkungan yang ada di sekitar kawasan. Maka dari itu diperlukannya program interpretasi yang dapat menjadikan edukasi lingkungan yang ada di Citamiang itu dapat sampai kepada wisatawan. Veverka (1994:23-25) menjelaskan bahwa penyampaian program interpretasi terdapat dua macam teknik komunikasi yaitu verbal dan non-verbal.

\section{a. Komunikasi verbal}

Kunci utama yang dipertimbangkan adalah pemilihan kata yang digunakan dalam penyampaian interpretasi sehingga dapat menyampaikan banyak pesan yang tersembunyi. Pesan verbal mencakup musik latar, tipe suara menurut jenis kelamin seperti laki-laki atau perempuan, muda atau tua, dan jenis obyek yang merupakan bagian dari penciptaan gambaran yang diinginkan oleh pendengar. Pesan ini juga merupakan komponen penghubung antara pendengar dengan pesan-pesan yang ingin disampaikan. 


\section{b. Komunkasi non-verbal}

Komunikasi ini memanfaatkan alat indera. Penyampaian interpretasi dapat dilakukan dengan menggunakan berbagai alat atau media interpretasi yang merupakan salah satu cara, metode, perekam suara atau peralatan yang bisa menyampaikan pesan interpretasi kepada publik. Komponen non-verbal diantaranya suara, aroma, rasa, tekstur, warna, symbol, penggunaan ruang, bahasa tubuh dan waktu. Berikut adalah rancangan program yang dibuat untuk non verbal.

Meet The Herbs adalah program verbal yang mana program ini ditujukan hanya untuk menjelaskan makna-makna edukasi tanaman herbal serta makna alam yang ada di kawasan Citamiang. Secara singkat peserta akan melakukan pengenaan tanaman herbal, manfaat serta habitatnya dan akan melakukan identifikasi sedehana untuk mengerti sedikit lebih jauh apa fungsi tanaman herbal tersebut.

Find More Indonesia adalah program non verbal yang dapat diaplikasikan di Citamiang. Program wisata ini dibuat bermalam dengan tema "Find More Indonesia" dirancang bagi calon Wisatawan yang ingin mengisi waktu luangnya untuk menikmati keindahan alam dan juga edukasi herbal yang ada di Citamiang. Program yang dinamai Find More Indonesia memiliki arti bahwa peserta yang mengikuti program ini akan lebih mengenal Indonesia. Program bermalam ini memiliki durasi 2 hari 1 malam yang dapat diikuti oleh Wisatawan dewasa berjumlah 5-10 orang.

\section{Kesimpulan}

Kawasan Citamiang yang dimiliki oleh Perhutani memiliki letak yang strategis dimana terletak di kawasan wisata puncak dan akses yang dapat ditempuh juga tidak terlalu sulit. Terdapat 6 (enam) atraksi ekowisata di Citamiang. Atraksi tersebut diantaranya adalah Nursery, Café 1911, Track Herbal, Camping Ground, Rumah Pemanen Hujan (RPH) dan juga selfie point Capung. Atraksi tesebut memiliki keunggulan yang berbeda-beda yang dapat dijadikan program interpretasi.

Sesuai dari hasil analisis Fishbein bahwa atraksi yang sangat dipercaya sebagai daya tarik ekowisata yang akan diunggulkan dalam program interpretasi adalah atraksi track herbal yakni dengan skor 2.04, untuk infrastruktur dengan skor tertinggi adalah jalan menuju Nursery dan tingkat kepercayaan wisatawan terhadap fasilitas pada Nursery dan Rumah Pemanen Hujan dengan Skor 1,8. Track herbal memiliki point edukasi yang penting untuk wisatawan yang berkunjung ke Citamiang, tingkat kepentingan tersebut memiliki skor 1.40, untuk infrastruktur dan fasilitas skor tertingggi ada pada Camping Ground. Pada dasarnya setiap atraksi memiliki perannya masing-masing. Namun, atraksi memiliki keunggulan masing-masing didalamnya, Tingkat kepentingan Track herbalpun sangat penting untuk ada dalam program wisata, dari hasil analisis bahwa track herbal menjadi yang utama untuk ada di dalam program interpretasi. Sikap wisatawan terhadap atraksi yang ada di Citamiang pada umumnya memasuki kategori 'baik' dengan Skor 7.20, selanjutnya untuk skor infrastruktur 10,43 dan fasilitas dengan skor 8,53.

Bentuk Interpretasi yang dapat diterapkan di Citamiang adalah bentuk interpretasi verbal dan non verbal. Kedua bentuk interpretasi ini sangat cocok untuk digunakan di Citamiang dalam mendukung bentuk interpretasi lain yang sudah tersedia. Seperti papan interpretasi, jalur dan label tanaman herbal. 


\section{Daftar Pustaka}

Ajzen, I. And Fishbein, M. (1965). Understanding Attitudes and Predicting Social ntice.

Alikodra H S. 2012. Konservasi Sumberdaya Alam dan Lingkungan; Pendekatan Ecosophy Bagi Penyelamatan Bumi. Yogyakarta: UGM Press.

Atkinson et al. 2002. Pengantar Psikologi. New York (US): Routledge Pr.

Avenzora R. 2008. Ekoturisme Teori dan Praktek. Banda Aceh: BRR NAD dan Nias.

Bowman K. 2011. Sustainable tourism certification and state capacity: keep it local, simple, and fuzzy. J International Culture, Tour, Hospital. 5: $\quad$ (269:281).

Doi:

http://dx.doi.org/10.1108/17506181111156961.

Cooper, Chris et al. 2005. Tourism : Principles and Practice, Third Edition. England: Pearson Education Ltd.

Connolly S T C S G. 2011. Make it memorable: customer experiences in winter amusement park. J International Culture, Tour, Hospital. 5:(8091). Doi:

http://dx.doi.org/10.1108/17506181111111780.

Damanik J, Weber H. 2006. Perencanaan Ekowisata dari Teori dan Aplikasi. Yogyakarta: PUSPAR UGM dan ANDI Yogyakarta.

Eplerwood M. 1999. The Ecotourism Society. Kota Kinabulu: The Righ Approach.

Hermantoro H. 2015. Kepariwisataan, Destsinasi Pariwisata dan Produk Pariwisata. Depok: Aditri Publishing.

Lorant D. 2011. Tourism ecology: towards the responsible, sustainable tourism future. $\mathbf{J}$ Worldwide Hospital and Tour Theme.
3:(210-

216).

Doi:

http://dx.doi.org/10.1108/17554211111142176.

Lucia, Segre. 2016. Intersectoral local development in Italy: the cultural, creative, and tourism industries. $\mathrm{J}$ International Culture, Tour, Hospital. Doi: https://doi.org/10.1108/IJCTHR- 03-20160032.

Martin D, Woodside G.A, Dehuang N. 2006. Etic interprenting of naive subjective personal introspections of tourism behaviour: Analyzing visitors' stories about experiencing Mumbai, Seoul, Singapore, and Tokyo. J International Culture, Tour, Hospital. 1: (14-44). Doi: www.emeraldinsight.com/1750-6182.htm.

Mason P. 2008. Tourism Impacts, planning and managemant. Burlington USA: Butterwoth- Heinemann publications.

Morissan. 2012. Metode penelitian survei. Jakarta. Kencana Prenadamedia Group.

Moscardo, G. 2014. Interpretation and tourism: holy grail or emperor's robes?. J Culture, Tour, Hospital Reseaarch. 8: $\quad$ (462:476).

Doi:

http://dx.doi.org/10.1108/IJCTHR-08-20140071.

Muntasib, EKSH. 2003. Interpretasi Wisata Alam. Laboratorium Rekreasi Alam Departemen 
Konservasi Sumberdaya Hutan dan Ekowisata. Bogor (ID): Fakultas Kehutanan. Institut Pertanian Bogor.

O'Sullivan T. 2010. More than words? Conversation analysis in arts marketing research. J International Culture, Tour, Hospital. 4: (2032). Doi: http://dx.doi.org/10.1108/17506181011024733.

Pitana I Gde, Diarta. 2009. Pengantar Ilmu Pariwisata. Andi Offset. Yogyakarta.

Sharpe G. 1982. Interpreting the environment. Washington (US): Outdoor Recreating College of Forest Resources University of Washington Seattle.

Singarimbun, Effendi. 1989. Metode Penelitian Survai. Jakarta. LP3ES.

Simamora.2008. Panduan Riset Prilaku Konsumen. Jakarta : Gramedia Pustaka.

Spillane J,J. 1987. Ekonomi Pariwisata (Sejarah dan Prospeknya). Penerbit Kanisius. Yogyakarta.

Sugiyono. 2012. Metode Penelitian Kuantitatif Kualitatif dan R\&D. Bandung:Alfabeta Bandung. The Ecotourism Society. 1993. Ekotourisme : Petunjuk untuk perencana dan pengelola. North Bennington: USAID.

Ting D I., Chin Cheng C F. 2016. Developing pro-environmental behaviour: ecotourism fieldtrip and experiences. J Sustain in Higher Education. Doi: https://doi.org/10.1108/IJSHE03-2016-0052.

Tilden F. 1977. Interpreting Our Heritage. New York (US). The University of North Corolina Press.

Veverka, J A. 1994. Interpertative master planning: for parks, historic sites, forests, zooz, and related tourism sites, for self-guided interpretative service, for interpretive exhibits, for guided program or tours. Falcon Press.

Wahab S. 1976. Tourism Management. Turin: Tpurism International Press.

Warpani S P, Warpani I P. 2007. Pariwisata dalam Tata Ruang Wilayah. Bandung. Institut Teknologi Bandung.

Wearing et al. 2009. Enhancing visitor experience through interpretation:an examination of influencing factors. Australia (AU). Cooperative research centre for sustainable tourism. 